\title{
Home accident or physical abuse: Evaluation of younger children presenting with trauma, burn and poisoning in the Pediatric Emergency Department
}

\author{
Emel Isıyel ${ }^{1}$, Özlem Tekşam¹${ }^{1}$, Dilşad Foto-Özdemir², Elif Özmert ${ }^{1}$, Ali Rıza Tümer ${ }^{3}$, \\ Gülsev Kale ${ }^{1}$ \\ Departments of ${ }^{1}$ Pediatrics, ${ }^{2}$ Child and Adolescent Psychiatry and ${ }^{3}$ Forensic Medicine, Hacettepe University Faculty of \\ Medicine, Ankara, Turkey. E-mail: eisiyel@gmail.com \\ Received: 4th April 2018, Revised: 30th September 2018, 10th November 2018, Accepted: 10th December \\ 2018
}

SUMMARY: Isıyel E, Tekşam Ö, Foto-Özdemir D, Özmert E, Tümer AR, Kale G. Home accident or physical abuse: Evaluation of younger children presenting with trauma, burn and poisoning in the Pediatric Emergency Department. Turk J Pediatr 2018; 60: 625-632.

Most cases of physical abuse and neglect refer to pediatric emergency clinics, and these patients are diagnosed as only home accidents. Cases that cannot be diagnosed and managed correctly are again exposed to severe trauma and consequently, they may die. The aim of this study is to evaluate the physical abuse and neglect in children younger than three years of age, admitted to the pediatric emergency department with the complaints of trauma, burn, drug poisoning and/or caustic ingestion. This prospective study included 132 patients who were admitted to the pediatric emergency department. Children were classified into three groups as "no abuse", "suspected abuse" and "abused" after being evaluated with a standard form. Additionally, suspected abuse and abused cases were evaluated once again by "The Team of Child Abuse and Neglect Evaluation, Research and Treatment" in Hacettepe University, İhsan Doğramacı Children's Hospital.

The frequency of the suspected abuse or abused cases in all burn, trauma and poisoning cases was found to be $7.5 \%$. It was noticed that 65 of the patients (49.2\%) were physically neglected considering the mechanism of occurrence of events. Unplanned pregnancy, absence of prenatal follow-up, high number of siblings, previous physical abuse in the family, absence of witness during the event, and hospitalization were statistically significant differences between no abuse and suspected abuse or abused cases $(p<0.05)$. Moreover, age group and income were significant risk factors in the logistic regression model for the patients who were thought to be suspected abuse/abused in univariate analyses (age group: Odds ratio (OR) 0.279 , 95\% confidence interval (CI) 0.085-0.723, p=0.0049; income: OR 2.323, 95\% CI 1.052-6.198, p=0.0345) In conclusion, most cases of physical abuse and neglect are referred to the pediatric emergency clinics, and these patients are misdiagnosed as home accidents. The physicians working in the emergency department should be informed and trained in recognizing the cases of abuse and neglect, making the differential diagnosis, identifying the high-risk families and appropriate physical and psychological treatment for the abused and neglected children.

Key words: trauma, burn, drug poisoning, risk factors of physical abuse, pediatric emergency clinics.

The frequency of physical abuse of children has increased all over the world and also in Turkey recently. ${ }^{1-5}$ Especially, children under three years of age are vulnerable and not able to express themselves; therefore, they are exposed to physical abuse much more than the elder ones. Children admitted to the pediatric emergency department with trauma, 
burn and/or poisoning should be evaluated carefully as these events could be a clue of abuse. Although some abused children are brought to an emergency department with serious injuries, others may present with subtle or occult injuries. ${ }^{6-8}$ Physicians working in emergency departments are often the initial contact and opportunity for child abuse and neglect victims to be recognized. A number of studies have shown that child abuse is a recurring condition, therefore, there is an obvious risk to the child when abuse is not recognized. For all these reasons, training the physicians dealing with children will improve their ability in diagnosing the abuses in the early period and may reduce the recurrences and deaths. ${ }^{9-11}$

In recent medical literature, medical evaluation of child abuse has received careful consideration because of specialists' increased awareness. ${ }^{1-3,5,9}$ When abuse is suspected concerning the patients' history and/or physical examination, patients should be evaluated by screening methods, and they should be directed to the specialists. ${ }^{1-3}$

This study aims to evaluate the physical abuse and neglect in young children admitted to the Pediatric Emergency Department with the complaints of trauma, burn, drug poisoning and/or caustic ingestion.

\section{Material and Methods}

This study was established in children younger than three years of age admitted with the complaints of trauma, burn, drug poisoning and/or caustic ingestion in six months period.

A questionnaire, consisting of three parts, was prepared for each patient. Age, gender, initial complaint, person who brought the patient to the hospital, caregiver, description of the event (how it occurred; place, time, person with the patient during the event; presence of any witness), history of the patient, growth and developmental status, physical examination, laboratory findings were evaluated in the first part.

Information about parental status, family composition, age and education of parents, the presence of a sibling, history of previous violence or physical abuse, psychiatric disorders in the family members, alcohol or substance misuse/abuse, family income were obtained in the second part of the questionnaire.

A reasonable cause to explain trauma, burn or poisoning, delay in admission, consistency between the child's developmental stage and level of skill and the event, additional clinical findings incompatible with the event, physical examination and laboratory findings suggesting abuse were inquired in the third part.

The patients were divided into three groups as "no abuse", "suspected abuse" and "abused" similar to Gencer and Oral's studies. ${ }^{12,13}$

Patients were initially evaluated for general approaches to trauma, burns, and poisonings. X-ray, ultrasonography (US) and/or computerized tomography/magnetic resonance (CT/MR) were applied if necessary. In addition, the cases that were considered suspicious or abusive according to the given criteria were also evaluated by the "Child Abuse and Neglect Research, Evaluation, and Treatment Team" of in the hospital". In these patients, fundus examination, bone scan and/or bone scintigraphy were performed. Developmental levels of children were assessed by administering Denver Developmental Screening test.

The study protocol was approved by the Institutional Ethics Committee with the decision number LUT 08/21-19 in 08/05/2008 and informed consents of the participants were also received.

\section{Statistical analysis}

Data were edited and analyzed using the Statistical Program for the Social Sciences 13. Demographic characteristics of the cases and information regarding the event were analyzed by using descriptive statistics. In evaluating the potential risk factors associated with physical abuse, Fisher's exact-test and Pearson chisquare tests were used. $P$ values $<0.05$ were considered statistically significant. Owing to the small number of cases defined as suspected or abused, univariate and multivariate analyses were conducted.

\section{Results}

We evaluated 132 patients during the study period (between January $1^{\text {st }}, 2008$ and June $\left.30^{\text {th }}, 2008\right)$. According to the defined criteria, abuse was not considered in 122 patients 
Table I. The Details of the Events.

\begin{tabular}{lc}
\hline Events & $\mathrm{N}(\%)$ \\
\hline Burning & $15(71.4)$ \\
Hot liquids (hot tea/water) & $5(23.8)$ \\
Hot bodies (stones/ovens) & $1(4.8)$ \\
$\quad$ Explosion of the catalytic furnace & $14(73.6)$ \\
Poisoning & $2(11.4)$ \\
Drug & $3(15.7)$ \\
Thinner & \\
Fabric softener, odoriferous substance in & $33(35.9)$ \\
the sink and polyvidone-iodine & $49(53.2)$ \\
Head & $7(7.6)$ \\
Multiple organ & $3(3.3)$ \\
Limb injuries & \\
Incisions and lacerations on the face & \\
\hline
\end{tabular}

(92.4\%), abuse was suspected in nine patients $(6.8 \%)$ and definitive abuse was considered in one patient $(0.8 \%)$. Physically neglect was evaluated in 65 of the patients $(49.2 \%)$ due to the lack of protection and/or appropriate supervision. Home accident was diagnosed in $67(51.2 \%)$ patients. Mean and median ages of the patients were $17.7 \pm 10.59$ months and 18 months, respectively. Seventy-two of the patients $(54.5 \%)$ were female, and 60 of them (45.5\%) were male.

\section{Features of the events}

Twenty-one (15.9\%) burned, 19 (14.3\%) poisoned (including caustic ingestions) and 92 trauma patients $(69.8 \%)$ were evaluated. In a patient with head trauma, it was also observed that the hand was burned by stove the day before admission. The details of the events and the classification of neglect cases were summarized in Table I and II.

\section{Physical findings}

Concurrent burns in one region and two or more regions were detected in 11 and 8 of the patients $(8.3 \%, 6.1 \%)$ respectively.

The following findings were detected in patients admitted with trauma: Hematoma or edema in 19 (14.4\%); incision and laceration in the skull in $8(6.1 \%)$; cuts, lacerations, ecchymosis on the face region in 6 (4.5\%); extremity swelling in 6 (4.5\%); extremity incision and laceration in 2 patients $(1.5 \%)$. A child was crushed by a television and moreover, his hand was burned by touching the stove the day before admission as well. Tachycardia was detected in one patient who had intoxication of salbutamol. There were many incisions, swelling, and ecchymosis in two patients $(1.5 \%)$, both of them falling from higher than two meters.

In 65 of the patients (49.2\%), there was no abnormality on physical examination.

Table II. The Classification of Neglect Cases.

\begin{tabular}{lclc}
\hline Event & $\mathrm{N}(\%)$ & Event & $\mathrm{N}(\%)$ \\
\hline Falling from the sofa / parent's bedstead & $17(13.0)$ & $\begin{array}{l}\text { Cutting his/her hand or foot with } \\
\text { the glass }\end{array}$ & $2(1.0)$ \\
Falling from the sibling's lap & $6(4.0)$ & Burning with hot water/tea & $16(12.0)$ \\
Falling from the home swing & $4(3.0)$ & Burning by touching stove/oven & $5(3.7)$ \\
Falling from the bench & $3(2.2)$ & Intoxication with/without drug & $10(7.5)$ \\
Falling from the stairs without barrier & $2(1.5)$ & & \\
while walking with the walker & & & \\
\hline
\end{tabular}


Table III. The Comparison of Demographic Characteristics and the Reason for Admission in Patients in Suspected/Abused and No Abuse Groups.

\begin{tabular}{|c|c|c|c|c|c|}
\hline \multirow[b]{2}{*}{ Parameters } & \multicolumn{4}{|c|}{ Groups } & \multirow[b]{2}{*}{$\mathrm{p}$} \\
\hline & $\begin{array}{c}\text { Suspected/ } \\
\text { abused }(\mathrm{n} / \mathrm{N})\end{array}$ & $\%$ & $\begin{array}{c}\text { No abuse } \\
(n / N)\end{array}$ & $\%$ & \\
\hline Age & & & & & 0.18 \\
\hline 0-6 month & $0 / 10$ & 0 & $24 / 122$ & 17.8 & \\
\hline 7-12 month & $2 / 10$ & 20 & $22 / 122$ & 16.0 & \\
\hline 13-24 month & $4 / 10$ & 40 & $46 / 122$ & 37.0 & \\
\hline 25-36 month & $4 / 10$ & 40 & $30 / 122$ & 24.0 & \\
\hline Gender & & & & & 0.75 \\
\hline Female & $6 / 10$ & 60 & $66 / 122$ & 54.0 & \\
\hline Male & $4 / 10$ & 40 & $56 / 122$ & 46.0 & \\
\hline The reason for the admissi & & & & & \\
\hline Burn & $2 / 10$ & 20 & $19 / 122$ & 15.5 & \\
\hline Poisoning & $1 / 10$ & 10 & $18 / 122$ & 14.7 & \\
\hline Head trauma & $2 / 10$ & 20 & $31 / 122$ & 25.4 & \\
\hline Multiple organ injuries & $3 / 10$ & 30 & $46 / 122$ & 37.7 & \\
\hline Extremity injuries & $2 / 10$ & 20 & $5 / 122$ & 4.0 & \\
\hline Lacerations on the face & $0 / 10$ & 0 & $3 / 122$ & 2.7 & \\
\hline
\end{tabular}

\section{Laboratory findings}

Bone scan in $41(31 \%)$, head and cervical radiography in $28(21.2 \%)$, computerized tomography in $14(10.6 \%)$, abdominal ultrasonography in $23(17.4 \%)$ and bone scintigraphy in 5 patients were performed.

Fractures were found in 14 of the patients who had trauma. Nondepressed fracture in one of the head bones in six $(4.5 \%)$, clavicle fracture in two $(1.5 \%)$, a humeral transverse fracture in one $(0.7 \%)$, humeral lateral condyle fracture in one $(0.7 \%)$, displaced fractures in the radius and ulna in one $(0.7 \%)$ patients were detected. Multiple fractures were detected in two patients, both of them fell from a height of two meters.

In 10 patients $(7.5 \%)$ fundus examination was performed, but no retinal hemorrhage was detected in any of them.

Nine patients were hospitalized and treated.

\section{Evaluation of risk factors}

Sociodemographic characteristics and risk factors of not abused and abused-suspected abuse patients are shown in table III and IV.

Six of the ten patients $(4.5 \%)$, suspected abuse or abused, were found to have no acceptable cause of burn, trauma or poisoning.
Seven patients $(5 \%)$ had delayed admissions to the hospital, two patients $(1.5 \%)$ had no appropriate developmental level for the match of the event, and two patients (1.5\%) had additional clinical findings incompatible with the story. None of the patients had multiple fractures and/or fractures or burns at different stages with the incompatible story.

Unplanned pregnancy, no prenatal follow-up, high number of siblings, previous physical abuse in the family, no witness during the event, and hospitalization were statistically found significant differences between no abuse and suspected abuse or abused cases $(p<0.05)$. Moreover, age group and income were found to be a significant risk factor in the logistic regression model for the patients who were thought to be suspected abuse/ abused in univariate analyses (age group: odds ratio (OR) $0.279,95 \%$ confidence interval (CI) $0.085-0.723, \mathrm{p}=0.0049$; income: OR 2.323, 95\% CI: 1.052-6.198, $\mathrm{p}=0.0345)$.

Three patients were hospitalized with the following details. First one was burned at home with an explosion, the second one developed tachycardia by taking salbutamol sulfate, and the third one was an unconscious patient who fell from a height of two meters. The last patient had brain death on the second 
Table IV. The comparison of the Risk Factors in Suspected/Abused and No Abuse Groups.

\begin{tabular}{|c|c|c|c|c|c|c|}
\hline \multirow{2}{*}{ Parameters } & & \multicolumn{4}{|c|}{ Groups } & \multirow[b]{2}{*}{$\mathrm{P}$} \\
\hline & & $\begin{array}{c}\text { Suspected/ } \\
\text { abused }(\mathrm{n} / \mathrm{N})\end{array}$ & $\%$ & $\begin{array}{l}\text { No abuse } \\
(\mathrm{n} / \mathrm{N})\end{array}$ & $\%$ & \\
\hline \multirow[t]{4}{*}{ Pregnancy } & & & & & & 0.006 \\
\hline & Wanted & $7 / 10$ & 70.0 & $119 / 122$ & 97.5 & \\
\hline & Unwanted & $3 / 10$ & 30.0 & $3 / 122$ & 2.5 & \\
\hline & Adopted & $0 / 10$ & 00.0 & $0 / 122$ & 0 & \\
\hline \multirow[t]{2}{*}{ Prenatal care } & & & & & & 0.046 \\
\hline & Present & $8 / 10$ & 80.0 & $119 / 122$ & 97.5 & \\
\hline \multirow[t]{6}{*}{ Number of siblings } & & & & & & 0.03 \\
\hline & None & $2 / 10$ & 20.0 & $58 / 122$ & 47.5 & \\
\hline & One & $6 / 10$ & 60.0 & $47 / 122$ & 38.5 & \\
\hline & Two & $1 / 10$ & 10.0 & $15 / 122$ & 12.2 & \\
\hline & Three & $1 / 10$ & 10.0 & $0 / 122$ & 0 & \\
\hline & Four or more & $0 / 10$ & 00.0 & $2 / 122$ & 1.8 & \\
\hline \multirow[t]{2}{*}{ Witness } & & & & & & 0.02 \\
\hline & Present & $6 / 10$ & 60.0 & $109 / 122$ & 89.3 & \\
\hline \multirow[t]{6}{*}{ Income } & & & & & & 0.02 \\
\hline & $<600$ Ł & $2 / 10$ & 20.0 & $2 / 122$ & 1.6 & \\
\hline & $600-1,000 も$ & $5 / 10$ & 50.0 & $38 / 122$ & 31.1 & \\
\hline & $1,000-1,500 €$ & $2 / 10$ & 20.0 & $47 / 122$ & 38.5 & \\
\hline & $>1,500 €$ & $1 / 10$ & 10.0 & $28 / 122$ & 23.0 & \\
\hline & Unstable & $0 / 10$ & 00.0 & $7 / 122$ & 5.7 & \\
\hline \multirow[t]{5}{*}{ Education of mother } & & & & & & 0.03 \\
\hline & Illiterate & $0 / 10$ & 00.0 & $0 / 122$ & 0 & \\
\hline & Primary school & $5 / 10$ & 50.0 & $20 / 122$ & 16.3 & \\
\hline & High school & $4 / 10$ & 40.0 & $71 / 122$ & 58.1 & \\
\hline & University & $1 / 10$ & 10.0 & $31 / 122$ & 25.6 & \\
\hline
\end{tabular}

day of admission, and finally, she died on the seventh day.

Details of the suspected abuse or abused patients are summarized in Table V.

\section{Discussion}

The incidence of suspected abuse or definitive abuse was $7.5 \%$ in our study. We found the overall mortality rate of $0.7 \%$ and $10 \%$ in suspected abuse or abused children. Estroff et al. ${ }^{14}$ divided the patients into two groups as accidental and non-accidental (AT and NAT) and they found abuse in $7.5 \%$ of 5,984 admissions with head, visceral and polytrauma. Mortality rate was $1.4 \%$ (AT) and $8.9 \%$ (NAT), respectively in their study. The overall mortality was $2 \%$ in this study. Moreover, it is showed that the NAT patients were younger $(1.8 \pm 3.3$ years $)$ than AT patients $(6.8 \pm 4.2$ years, $\mathrm{p}<0.01)$. Deans et al. ${ }^{15}$ demonstrated that patients of recurrent NAT had significantly higher mortality compared with patients of a single episode of NAT $(25 \%$ vs. $10 \%)$. The frequency of abuse alters between $18-24 \%$ in patients with trauma in different studies. $11,14,15$ These studies focused on more well-known trauma such as head trauma and fractures related to abuse; however, in our study, not only traumas but also burns and poisonings that might be related to abuse were taken into consideration. Gencer et al. ${ }^{13}$ found the rate of the suspected abuse or definitive abuse as $16 \%$ investigating the abuse in any kind of home accidents including falling down, foreign object ingestion, intoxication, burn, electrical shock and others. Taitz and colleagues ${ }^{16}$ demonstrated the rate of suspected abuse or definitive abuse children as $30 \%$ evaluated with fractures in 


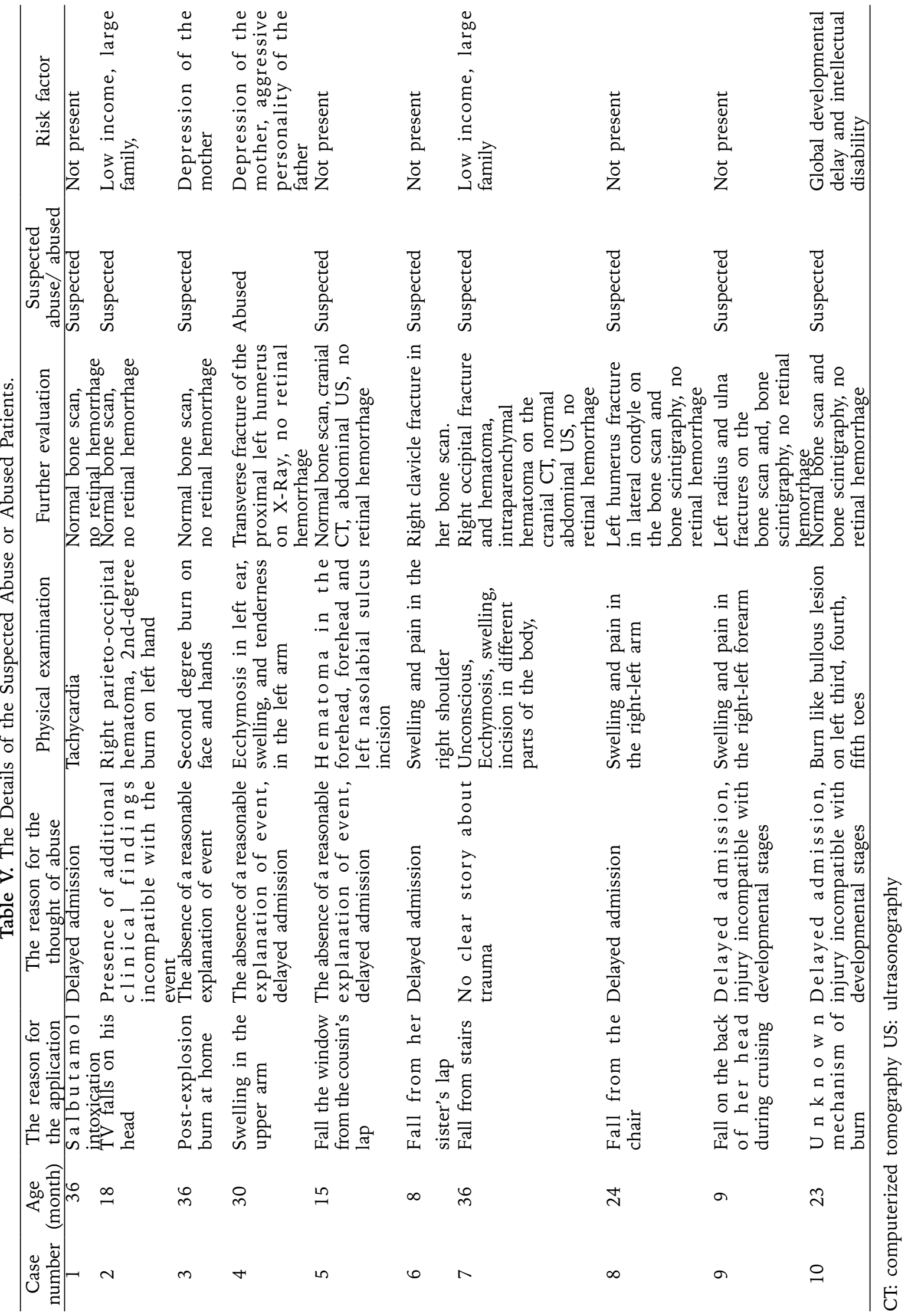


the emergency department, and only one child was referred to child protection for further evaluation.

The ages and the education levels of the parents were comparable. However, the increase in education level of the mother was negatively correlated with the rate of abuse in our study. Five mothers $(50 \%)$ of the suspected abuse or definitive abuse patients graduated from primary school, four $(40 \%)$ from high school and only one mother (10\%) graduated from the university. Putnam-Horstein et al. ${ }^{17}$ noted that maternal education levels of the children referred to child protective services for abuse were high school or below with the $78.8 \%$.

It was also found that an increase in the number of siblings raised the likelihood of abuse. This suggests that the probability of abuse in large families is high. As the number of children in the family increases, the mother or father can experience difficulties in dealing with children, and for this reason, they can apply physical violence to their children with behavior such as forging and pushing. The presence of physical violence in the family was found to be statistically significant in the scope of physical abuse. In our study, three (30\%) of the suspected abuse or abused cases were found to have domestic physical violence. In one study, it was shown that families with domestic violence are 4.9 times more likely to have child abuse than those without it. It has been found that women who have been subjected to violence by their husbands apply more severe punishments and worse treatment to their children. ${ }^{18-20}$

In our study, it was determined that the mothers of two suspected abuse or abused patients were being followed with diagnosis of depression. Psychiatric disorders in the parents were not found statistically significant in our study. However, the presence of psychiatric diseases of mother and/or father was found to be as high as $20 \%$ among the patients thought to be abused in the study of Şahiner et al. ${ }^{20}$

A statistically significant relationship was found between income and abuse in our study as the probability of abuse increased when income level decreased. Some studies have found low income to be associated with neglect and abuse; however, income was not found to be a significant correlate of the neglect and abuse in some other studies. ${ }^{21-24}$

Taitz J et al. ${ }^{16}$ noted eleven of fourteen children with humerus fractures were abused in their study relating the evaluation of long bone fractures with abuse. In another study by O'Neill et al. ${ }^{25}$ humerus fractures were shown as the most common fractures in 28 abused children.

In our study, a 30-month-old girl was brought to our hospital with complaints of swelling in the left arm and a transverse fracture of the proximal humerus was detected on the radiogram. In her history, the family noticed the day before that the child could not move her arm, but they did not know how the fracture occurred. This child was diagnosed with abuse because of the following reasons and risk factors: no anxiety in the parents about how the fracture occurred, delay in admitting to the hospital, no reasonable cause to explain the trauma, ecchymosis in the earlobe recognized by the physician that the parent could not explain, depression of the mother and aggressive personality of the father. Therefore, the child and the family were commenced to be monitored.

In conclusion; most cases of physical abuse and neglect referred to pediatric emergency clinics are diagnosed with only home accidents and abuse could be missed. Cases that cannot be diagnosed and managed correctly are again exposed to severe trauma, consequently, the missed diagnosis can cause grave morbidity and even death of the child. The physicians working in the emergency clinics should be informed and trained in recognizing the cases of abuse and neglect, making the differential diagnosis, identifying the high-risk families and appropriate physical and psychological treatment for the abused and neglected child. Finally, a multidisciplinary approach is needed in the treatment and follow-up of patients diagnosed with physical abuse and neglect.

\section{REFERENCES}

1. Yurdakök K. Çocuk istismar ve ihmali, tanım ve risk faktörleri. Katkı Pediatri Dergisi 2010; 32: 423-433.

2. Tekşam Ö. Çocuk acil ünitesinde istismar ve ihmal vakalarının tanınması ve uygun yaklaşım. Katkı Pediatri Dergisi 2010; 32: 435-448.

3. Wheeler KK, Shi J, Xiang H, Haley K, Groner JI. Child maltreatments in U.S. emergency departments: Imaging and admissions. Child Abuse Negl 2017; 69: 96-105. 
4. Davidson-Arad B, Benbenishty R, Chen W, Glasser S, Zur S, Lerner-Geva L. Distinguishing neglect from abuse and accident: analysis of the case files of a hospital child protection team in Israel. Health Soc Care Community 2010; 18: 614-623.

5. Claudet I, Gurrera E, Honorat R, Rekhroukh H, Casasoprana A, Grouteau E. Home falls in infants before walking acquisition. Arch Pediatr 2013; 20: 484-491.

6. Leventhal JM. Thinking clearly about evaluations of suspected child abuse. Clin Child Psychol Psychiatry 2000; 5: 139-147.

7. Tiyyagura G, Gawel M, Koziel JR, Asnes A, Bechtel $\mathrm{K}$. Barriers and facilitators to detecting child abuse and neglect in general emergency departments. Ann Emerg Med 2015; 66: 447-454.

8. Christian CW; Committee on Child Abuse and Neglect, American Academy of Pediatrics. The evaluation of suspected child physical abuse. Pediatrics 2015; 5: 1337-1354

9. Ekinci S. Fiziksel çocuk istismarı. Katkı Pediatri Dergisi 2010; 32: 625-631.

10. Wood JN, Fakeye O, Feudtner C, Mondestin V, Localio $\mathrm{R}$, Rubin DM. Development of guidelines for skeletal survey in young children with fractures. Pediatrics. 2014; 134: 45-53.

11. Wood JN, Fakeye O, Mondestin V, Rubin DM, Localio R, Feudtner C. Development of hospital-based guidelines for skeletal survey in young children with bruises. Pediatrics 2015; 135: 312-320.

12. Oral R, Blum LK, Jonhson C. Fractures in young children: Are physicians in the emergency department and orthopedic clinics adequately for possible abuse? Pediatr Emerg Care 2003; 19: 148-153.

13. Gencer O, Ozbek A, Bozabali R, Cangar S, Miral S. Suspected child abuse among victims of home accidents being admitted to the emergency department. Pediatr Emerg Care 2006; 22: 794-803.

14. Estroff JM, Foglia RP, Fuchs JR. A comparison of accidental and nonaccidental trauma: It is worse than you think. J Emerg Med 2015; 48: 274-279.
15..Deans KJ, Thackeray J, Askegard-Giesmann JR, et al. Mortality increases with recurrent episodes of nonaccidental trauma in children. J Trauma Acute Care Surg 2013; 75: 161-165.

16. Taitz J, Moran K, O’Mera M. Long bone fractures in children under 3 years of age: Is abuse being missed in emergency department presentations? J Paediatr Child Health 2004; 40: 170-174.

17. Putnam-Hornstein E, Cleves MA, Licht R, Needell B. Risk of fatal injury in young children following abuse allegations: Evidence from a prospective, populationbased study. Am J Public Health 2013; 103: 39-44.

18. Şahin F. Çocuk İstismarının Tanımı, Epidemiyolojisi ve Multidispliner Yaklaşımın Önemi. Çocuk İstismarı ve İhmaline Multidisipliner Yaklaşım, Ankara: Ankara Üniversitesi Basımevi; 2006: 5-8.

19. Rumm PD, Cummings P, Krauss MR, Bell MA, Rivara FP. Identified spouse abuse as a risk factor for child abuse. Child Abuse Negl 2000; 24: 1375-1381.

20. Şahiner ÜM, Yurdakök K, Kavak US, Çetin İ. Tıbbi açıdan çocuk istismarı. Katkı Pediatri Dergisi 2001; 22: $276-277$.

21. Brown J, Cohen P, Johnson J, Salzinger S. A longitudinal analysis of risk factors for child treatment: Findings of a 17 year prospective study of officially recorded and self reported child abuse and neglect. Child Abuse Negl 1998; 22: 1065-1078.

22. Lee B, Goerge R. Poverty, early child bearing and child maltreatment: A multinominal analysis. Child Youth Serv Rev 1999; 21: 755-780.

23. Connell-Carrick K. Ecological correlates of neglect in infants and toddlers. J Interpers Violence 2006; 21 : 299-316.

24. King A, Farst KJ, Jaeger MW, Onukwube JI, Robbins J. Maltreatment -related emergency department visits among children 0 to 3 years old in the United States. Child Maltreat 2015; 20:151-161.

25. O'Neill JA. Patterns of injury in the battered child syndrome. J Trauma 1973; 13: 332-339. 